Check for updates

Cite this: RSC Adv., 2018, 8, 12808

\title{
Modification of graphene oxide film properties using KrF laser irradiation
}

\author{
Somayeh Mortazavi, ${ }^{a}$ Mahmoud Mollabashi, (D) *a Rasoul Barri, ${ }^{\text {b }}$ Kevin Jones, ${ }^{c}$ \\ John Q. Xiao, ${ }^{\text {b }}$ Robert L. Opilacd and S. Ismat Shah*bc
}

Modification of various properties of graphene oxide (GO) films on $\mathrm{SiO}_{2} / \mathrm{Si}$ substrate under $\mathrm{KrF}$ laser radiation was extensively studied. X-ray diffraction, X-ray photoelectron spectroscopy, Raman spectroscopy and the electrical resistance measurements were employed to correlate the effects of laser irradiation on structural, chemical and electrical properties of GO films under different laser fluences. Raman spectroscopy shows reduced graphene oxide patterns with increased $I_{2 D} / I_{G}$ ratios in irradiated samples. X-ray photoelectron spectroscopy shows a high ratio of carbon to oxygen atoms in the reduced graphene oxide (rGO) films compared to the pristine GO films. X-ray diffraction patterns display a significant drop in the diffraction peak intensity after laser irradiation. Finally, the electrical resistance of irradiated GO films reduced by about four orders of magnitudes compared to the unirradiated GO films. Simultaneously, reduction and patterning of GO films display promising fabrication technique that can be useful for many graphene-based devices.

Received 4th January 2018

Accepted 27th March 2018

DOI: $10.1039 / \mathrm{c} 8 \mathrm{ra00097b}$

rsc.li/rsc-advances

photoresist and fabrication of various masks to produce the

\section{Introduction}

Graphene has been the subject of much research because of its unique electrical, thermal and mechanical properties. It is a promising material in a wide variety of fields including optics and electronics, solar cells, light emitting devices, touch screens, flat panel displays and photovoltaic applications. Following exciting research on graphene, graphene oxide (GO) and reduced graphene oxide ( $\mathrm{rGO}$ ) have attracted great interest as a replacement of graphene in some aspects, like facile synthesis and potential applications in electronics and optoelectronics, circuits, sensors and supercapacitors. ${ }^{1-24}$ The Hummers method is the most promising fabrication process in which the precursor commonly undergoes a reduction process for mass production of the graphene-based material. RGO shows completely different chemical and physical properties compared to GO. Although a complete conversion of GO to graphene has proven to be difficult, partial rGO with improved electrical conductivity can be relatively easily obtained..$^{13-29}$

In addition to the reduction process, many applications of the material require simultaneous patterning on various substrates. However, the common patterning methods need

${ }^{a}$ School of Physics, Iran University of Science and Technology, Tehran 16844, Iran. E-mail: mollabashi@iust.ac.ir; Fax: +98 7302 1452; Tel: +98 73225858

${ }^{b}$ Department of Physics \& Astronomy, University of Delaware, Newark, DE 19716, USA. E-mail: ismat@udel.edu

${ }^{c}$ Department of Materials Sciences and Engineering, University of Delaware, Newark, DE 19716, USA

${ }^{d}$ Department of Electrical and Computer Engineering, University of Delaware, Newark, DE 19716, USA desired patterns. A laser reduction method has been used to produce rGO patterns on GO films, which eliminates other complex methods such as lithography after primarily reduction process. ${ }^{30,31}$

So far, many studies have investigated laser patterning of graphene, ${ }^{32-39}$ graphite oxide ${ }^{39,40}$ and GO films. ${ }^{41-46}$ In particular, patterning GO films were performed using different lasers irradiation on various substrates. ${ }^{41-49}$ In one study, ${ }^{29}$ direct writing of conductive microcircuits on GO films was demonstrated using femtosecond laser irradiation. The removal of oxygen functional groups was confirmed by XPS studies and a reduction of electrical resistance was observed in rGO films. However, there isn't any evidence of transformation to the graphene-like structures in irradiated GO films, because no increase of $2 \mathrm{D}$ band was observed in Raman spectrum of irradiated GO film. The increase of the band intensity confirms transformation to the graphene-like structures. Another study ${ }^{47}$ of laser irradiation of GO films on a glass substrate was reported using a femtosecond laser with $800 \mathrm{~nm}$ wavelength. Nevertheless, the measured range of Raman spectra was limited just to $D$ and $\mathrm{G}$ bands and there was no report of the $2 \mathrm{D}$ band at Raman spectra of their irradiated film. Several other authors have also looked at the interaction of $\mathrm{KrF}$ laser and GO film ${ }^{48,50,51}$ due to a close coincidence of the laser wavelength with those of chemical bonds of the material. In one study, ${ }^{38}$ producing the transparent circuit of reduced electrical resistance was reported on GO thin films on glass substrate. Nevertheless, any chemical analysis or structural investigations of irradiated GO film were not represented in this study. In another report ${ }^{50}$ the effect of 
$\mathrm{KrF}$ laser irradiation on GO films has been studied with a different number of laser pulses and laser fluences. The experiments were carried out in a vacuum and in a $\mathrm{H}_{2}$ atmosphere and the reduction process of GO films was found to be more efficient under $\mathrm{H}_{2}$ atmosphere than the vacuum. In a more recent report, ${ }^{51}$ laser reduction of GO films was studied using KrF, Ti:sapphire and CW lasers irradiation. The substrate used in their work was chosen to be polyethylene terephthalate (PET) because of its flexibility and suitability for supercapacitors. A comparison of the performance of each laser on a reduction of GO films at one certain laser fluence was reported and then, the effect of pulse duration on how reduction process of GO films was investigated. Raman and XPS data of GO films irradiated with $\mathrm{KrF}$ laser showed better results than those irradiated with femtoseconds and CW lasers. However, investigation of electrical resistance changes of irradiated GO films is absent in their study. The laser irradiation of GO films can result in fabrication of conductive circuits on insulator GO films that are attractive in microelectronic applications.

In the present study, the effect of KrF laser irradiation is investigated to improve various properties of GO films under different laser fluences in ambient atmosphere. $\mathrm{SiO}_{2} / \mathrm{Si}$ was chosen as a substrate because it is particularly attractive for microelectronics applications. A wide variety of characterization techniques was employed to monitor various properties of irradiated GO films included Raman spectroscopy, XPS, XRD, and AFM. These characterizations are necessary to completely understand the laser reduction process. More importantly, our study contains the investigation of the electrical resistance change of irradiated GO films under different laser fluence. The resultant rGO patterns of significantly different properties were obtained compared to the pristine GO films. We believe that our report is a comprehensive study of the laser irradiation process of GO thin films that includes characterization of various properties of irradiated films under similar irradiation conditions and on the same samples.

\section{Experimental details}

GO (Graphenea) used in the experiments was prepared via a modified Hummers method with a concentration $4 \mathrm{mg} \mathrm{ml}^{-1}$ in water. Gold electrodes were deposited on $\mathrm{a} \mathrm{SiO}_{2} / \mathrm{Si}$ substrate for electrical resistance measurements. GO thin films were obtained by spin coating GO aqueous suspension on the substrate at $1000 \mathrm{rpm}$ for $60 \mathrm{~s}$ and then dried at $60{ }^{\circ} \mathrm{C}$. A pulsed $\mathrm{KrF}$ excimer laser of $248 \mathrm{~nm}$ wavelength and $10 \mathrm{~ns}$ pulse duration was used for the patterning of GO films. A schematic of steps proposed to prepare GO films and laser processing system is shown in Fig. 1(a and b), respectively. A $75 \mathrm{~mm}$ lens focuses the laser beam on the sample. GO film has been translated perpendicular to the laser beam and $100 \mu \mathrm{m} \mathrm{s}^{-1}$ scanning speed was chosen for laser treatment of samples. Laser treatment process of GO samples was carried out at ambient and at room temperature.

Raman spectrometer (Thermo Fisher, DXR) with a laser source $532 \mathrm{~nm}$ and a spot size $0.7 \mu \mathrm{m}$ was used to characterize GO films. Surface topography was measured using atomic force microscope (AFM), model: Anasys NanoIR2, in the contact mode. X-ray diffraction (XRD) patterns were recorded using a Bruker X-ray diffractometer with $\mathrm{Cu} \mathrm{K} \alpha$ irradiations operated at $40 \mathrm{kV}$ and $30 \mathrm{~mA}$. X-ray photoelectron spectroscopy (XPS) was employed to determine chemical states of GO films using a Physical Electronics PHI 5600 spectrometer with an $\mathrm{Al} \mathrm{K \alpha}$ radiation source $(1486.7 \mathrm{eV})$ with an energy resolution of FWHM $0.7 \mathrm{eV}$ for sputtered clean $\mathrm{Ag}$ foil $\left(\mathrm{Ag} 3 \mathrm{~d}_{5 / 2}\right)$ at pass energy $11.75 \mathrm{eV}$. De-convolution of all XPS data were performed using

(a)

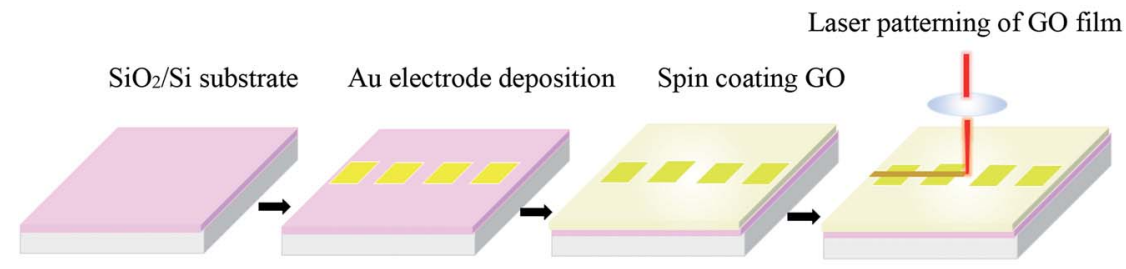

(b)

(c)
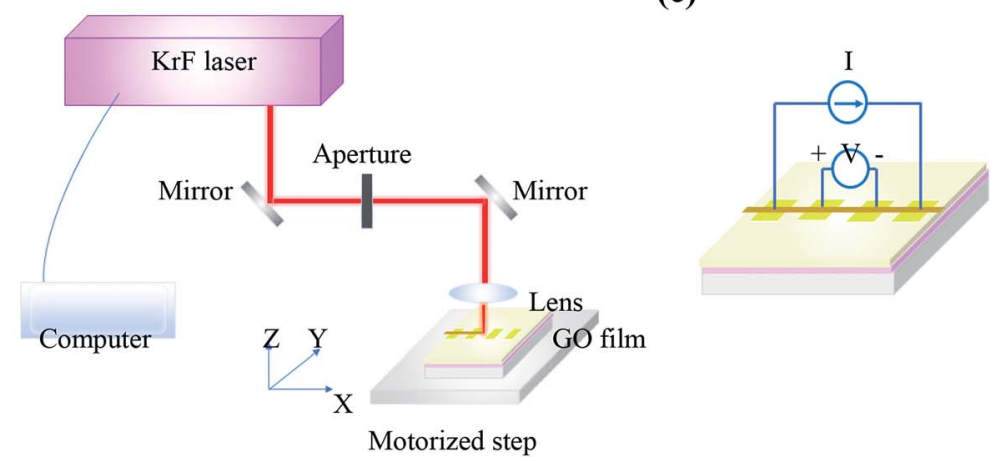

Fig. 1 Schematic of (a) steps proposed to prepare $\mathrm{GO}$ films on $\mathrm{SiO}_{2} / \mathrm{Si}$ substrate, (b) $\mathrm{KrF}$ laser treatment system of the films and (c) electrical resistance measurements of irradiated films. 
CasaXPS software with general forms of Gaussian and Lorentzian line shapes. Electrical resistance measurements were conducted using a 4-point probe method (Fig. 1(c)).

\section{Results and discussion}

Prepared GO films were exposed to $\mathrm{KrF}$ laser in an air atmosphere at laser fluences ranging from 4 to $72 \mathrm{~mJ} \mathrm{~cm}^{-2}$. Fig. 2(a) indicates AFM images of two separate areas of GO and irradiated GO at a certain laser fluence. The irradiation trace can be clearly observed in Fig. 2(a). Some islands also exist near irradiation trace due to slightly ablated GO layers that covered unirradiated area. AFM 2D and 3D topography of unirradiated and irradiated areas in smaller scan areas were shown in Fig. 2(b) and (c), respectively. AFM images show that the laser irradiation process increases roughness on the surface of irradiated GO film compared to the unirradiated area which showed a relatively smooth surface.

Raman spectroscopy was used to study laser reduction process of GO films. The typical Raman spectrum of GO shows the D and $\mathrm{G}$ bands around 1350 and $1580 \mathrm{~cm}^{-1}$. The $\mathrm{D}$ band is assigned to the out-of-plane breathing mode of the $\mathrm{sp}^{2}$ carbon atoms due to defects. The $\mathrm{G}$ band of graphene is produced by the in-plane vibration of $\mathrm{C}$ atoms and identifies the first order Ramanallowed mode of graphene. ${ }^{25,47} 2 \mathrm{D}$ band $\left(2690 \mathrm{~cm}^{-1}\right)$ is the second order of $\mathrm{D}$ band, however, there is no need for the presence of the defects for its activation. Fig. 3(a) compares Raman spectrum of GO film with those of GO films irradiated with laser fluences from 18 to $32 \mathrm{~mJ} \mathrm{~cm}{ }^{-2}$. All Raman spectra were normalized to $\mathrm{G}$ band to more correctly evaluate changes of the $2 \mathrm{D}$ band with laser fluence: since this peak is known as a fingerprint of single-layer graphene. The Raman spectrum of the pristine GO film revealed a strong D band with the intensity comparable to the $\mathrm{G}$ band and a broad low-intensity $2 \mathrm{D}$ band. However, stronger and narrower 2D bands appeared in Raman spectra of irradiated GO films (Fig. 3(b)). The intensity of the peak increases as laser fluence goes up confirming the transformation to the graphene-like structures as a result of the laser irradiation process. It is established that $I_{\mathrm{D}} / I_{\mathrm{G}}$ ratio shows the degree of defects and $I_{2 \mathrm{D}} / I_{\mathrm{G}}$ ratio indicates $\mathrm{sp}^{2} \mathrm{C}=\mathrm{C}$ bond in graphene structure. In order to a comparison of rGO films quality produced under various laser fluences, the trend of $I_{2 \mathrm{D}} / I_{\mathrm{G}}$ and $I_{\mathrm{D}} / I_{\mathrm{G}}$ changes with increasing laser fluence was shown in Fig. 3(c). It is clear that increasing laser fluence causes a higher $I_{2 \mathrm{D}} / I_{\mathrm{G}}$ ratio and it was expected that increasing laser fluence further results in higher values of $I_{2 \mathrm{D}} / I_{\mathrm{G}}$. The increasing $I_{\mathrm{D}} / I_{\mathrm{G}}$ ratio in the figure also (a)

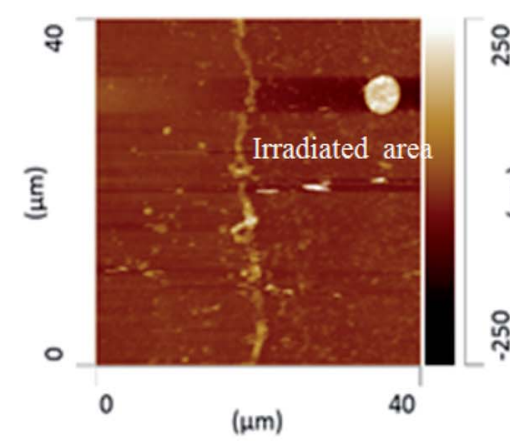

(b)

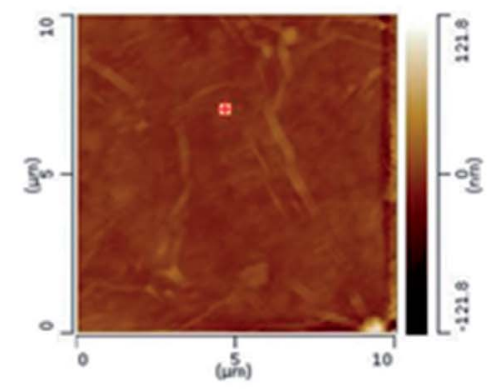

(c)

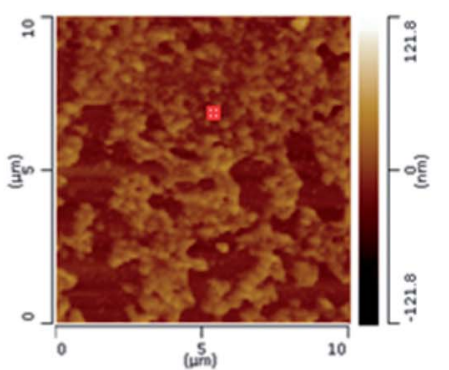

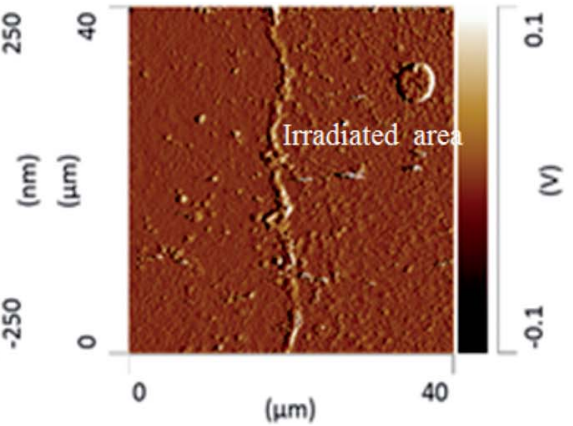
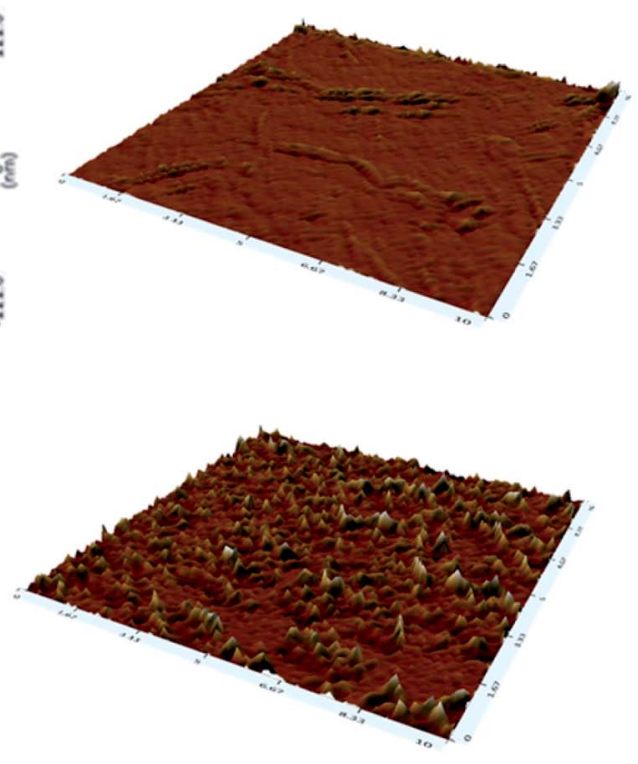

Fig. 2 (a) AFM topography of GO film containing unirradiated and irradiated areas and (b and c) AFM 2D and 3D topography of unirradiated and irradiated areas in a $10 \times 10 \mu \mathrm{m}^{2}$ area scan, respectively. 

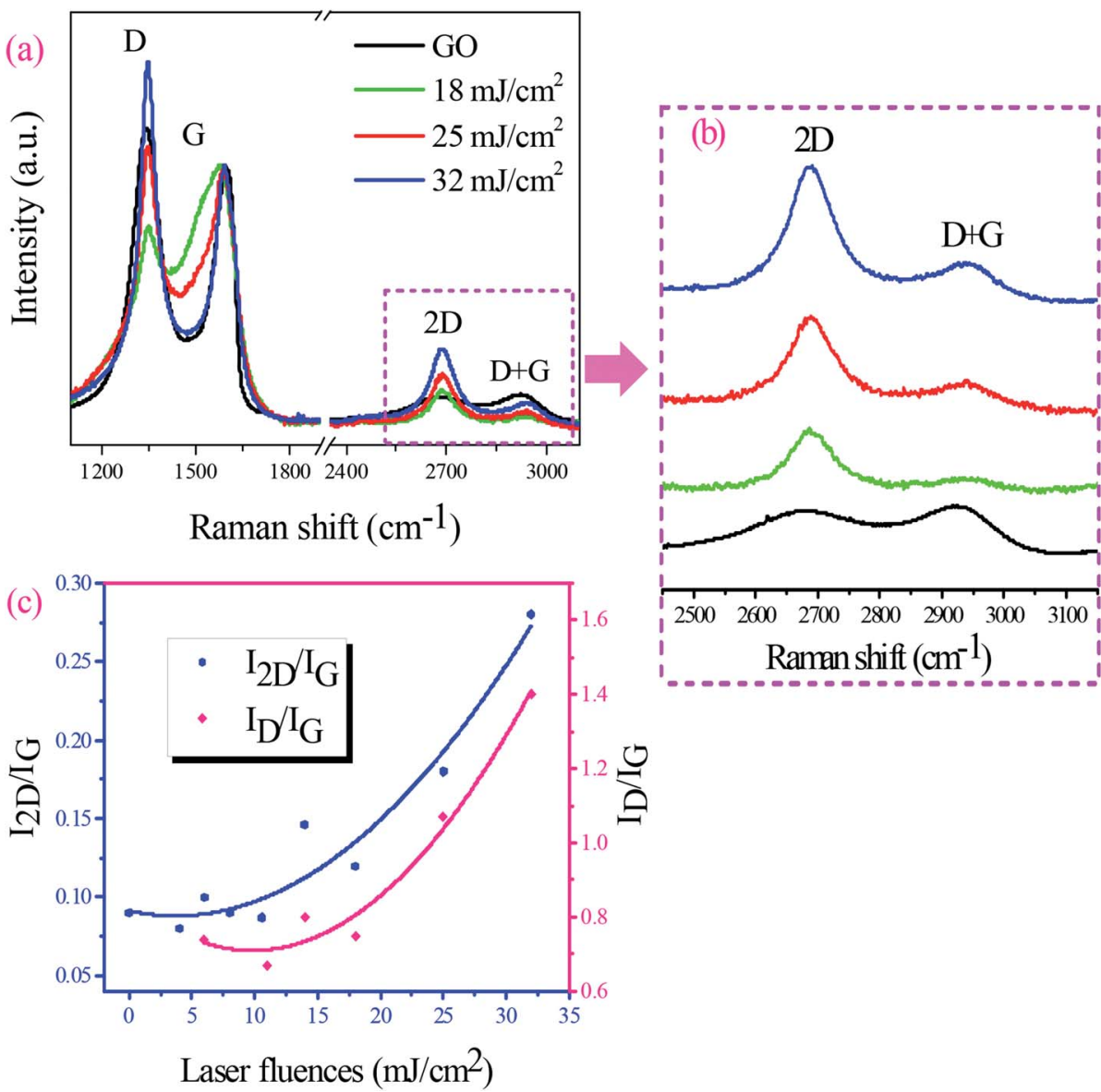

Fig. 3 (a) Raman spectra of GO and rGO at several different laser fluences. All Raman spectra were normalized to G band, (b) the enlarged 2D region of $\mathrm{rGO}$ films at several different laser fluences and (c) dependence of $I_{2 D} / I_{G}$ and $I_{D} / I_{G}$ ratios of GO and $\mathrm{rGO}$ films on laser fluence.

shows producing further defects during the laser irradiation process. Table 1 also summarizes the positions of each band, bands intensity ratios, and FWHM of the 2D band for rGO films at different laser fluences. The $2 \mathrm{D}$ band of irradiated GO films was centered at around $2690 \mathrm{~cm}^{-1}$. A decrease of FWHM of the $2 \mathrm{D}$ band was observed by increasing laser fluence as $I_{2 \mathrm{D}} / I_{\mathrm{G}}$ ratio increased for GO film irradiated at these laser fluences. The least FWHM value $96.36 \mathrm{~cm}^{-1}$ and the highest $I_{2 \mathrm{D}} / I_{\mathrm{G}}$ ratio 0.28 were calculated for GO film irradiated at $32 \mathrm{~mJ} \mathrm{~cm}^{-2}$ laser fluence. The lower value of $I_{\mathrm{D}} / I_{\mathrm{G}}$ ratio shows lesser defects and higher value of

Table 1 Characteristics of Raman bands of GO and rGO films at different laser fluences

\begin{tabular}{|c|c|c|c|c|c|c|c|}
\hline \multirow{2}{*}{$\begin{array}{l}\text { Laser fluence } \\
\left(\mathrm{mJ} \mathrm{cm}^{-2}\right)\end{array}$} & \multicolumn{3}{|c|}{$\begin{array}{l}\text { Band } \\
\text { position }\left(\mathrm{cm}^{-1}\right)\end{array}$} & \multirow{2}{*}{$\frac{\text { FWHM }\left(\mathrm{cm}^{-1}\right)}{2 \mathrm{D}}$} & \multicolumn{3}{|c|}{$\begin{array}{l}\text { Band } \\
\text { intensity ratios }\end{array}$} \\
\hline & D & G & $2 \mathrm{D}$ & & $I_{\mathrm{D}} / I_{\mathrm{G}}$ & $I_{2 \mathrm{D}} / I_{\mathrm{G}}$ & $I_{2 \mathrm{D}} / I_{\mathrm{D}}$ \\
\hline GO & 1341 & 1597 & 2687 & 313.83 & 1.1 & 0.09 & 0.08 \\
\hline 6 & 1345 & 1584 & 2687 & 305.79 & 0.74 & 0.1 & 0.13 \\
\hline 14 & 1348 & 1584 & 2689 & 302.16 & 0.8 & 0.14 & 0.17 \\
\hline 18 & 1349 & 1582 & 2686 & 239.28 & 0.75 & 0.12 & 0.16 \\
\hline 25 & 1349 & 1591 & 2689 & 93.43 & 1.1 & 0.18 & 0.16 \\
\hline 32 & 1347 & 1589 & 2690 & 96.93 & 1.4 & 0.28 & 0.2 \\
\hline
\end{tabular}

$I_{2 \mathrm{D}} / I_{\mathrm{G}}$ ratio indicates the transformation to the graphene-like structures that results in higher charge mobility.

The chemical states of pristine GO film and GO film irradiated at $32 \mathrm{~mJ} \mathrm{~cm}^{-2}$ laser fluence were investigated by the use of XPS. Fig. 4(a) shows XPS results of the films and covers the carbon and oxygen regions. While pristine GO film represents $\mathrm{C} / \mathrm{O}$ ratio of 0.65 , the value reaches to about 1 after laser irradiation. The deconvolution of the $\mathrm{C} 1 \mathrm{~s}$ peak of the films is shown in Fig. 4(b). The C1s spectrum composed of reduced carbon species ( 284.5 and $285.6 \mathrm{eV})$, single bond carbon-oxygen components $(\sim 286.7 \mathrm{eV})$ and double bond carbon-oxygen components $(\sim 288.3 \mathrm{eV})$ as labeled in Fig. 4(b). In the XPS data of irradiated GO film, a strong peak corresponding to $\mathrm{sp}^{2}$ carbon bonds at $284.5 \mathrm{eV}$ along with a small peak associated with the oxygenated functional groups are observed indicating the significant removal of oxygen contents. In addition, another lower intensity peak assigned to $\mathrm{sp}^{3}$ carbon bonds also exists in rGO film, which was also observed by others researchers. ${ }^{50}$

Table 2 represents $\mathrm{C} / \mathrm{O}$ ratios and the atomic percentage of carbon components respectively derived from the XPS survey and C1s spectra for GO and rGO films. Based on the results, it seems KrF laser irradiation process mostly eliminates single bond carbon-oxygen components while the $\mathrm{sp}^{2}$ carbon bonds remain intact and then results in producing rGO patterns with a high $\mathrm{C} / \mathrm{O}$ ratio. 

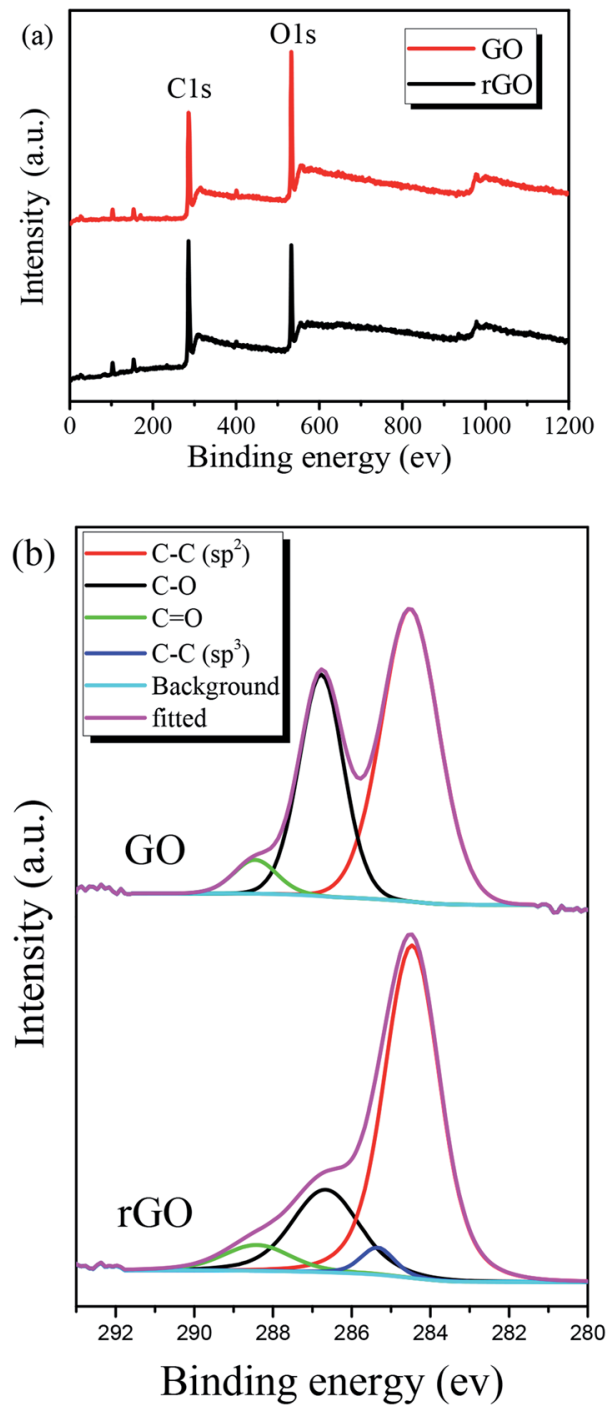

Fig. 4 (a) XPS survey and (b) C1s XPS spectra of GO and rGO films at 32 $\mathrm{mJ} \mathrm{cm} \mathrm{cm}^{-2}$ laser fluence.

To more carefully evaluate the reduction process of GO film on $\mathrm{SiO}_{2} / \mathrm{Si}$ substrate under laser irradiation, XRD patterns were recorded in a range of $2 \theta$ from $5^{\circ}$ to $75^{\circ}$. The XRD pattern of graphite exhibits a peak located at $\sim 26.4^{\circ}$. This peak corresponds to a (002) reflection of graphite with a thickness of $\sim 3.37$ $\AA$ of atomically flat graphene sheets. The position of the diffraction peak is shifted to a lower angle for GO due to increased interlayer spacing arising from the presence of oxygen functional groups. Fig. 5 compares the XRD pattern of rGO film

Table $2 \mathrm{C} / \mathrm{O}$ ratios and atomic percentages of carbon components of GO and rGO films derived from XPS survey and C1s spectrum

\begin{tabular}{lllll}
\hline & & $\begin{array}{l}\mathrm{C}-\mathrm{C}\left(\mathrm{sp}^{2} \text { and } \mathrm{sp}^{3}\right) \\
(284.5 \text { and } 285.6 \mathrm{eV})\end{array}$ & $\begin{array}{l}\mathrm{C}-\mathrm{O} \\
(286.7 \mathrm{eV})\end{array}$ & $\begin{array}{l}\mathrm{C}=\mathrm{O} \\
(288.3 \mathrm{eV})\end{array}$ \\
\hline $\mathrm{C} / \mathrm{O}$ & & 37 & 20 \\
$\mathrm{GO}$ & 0.65 & 43 & 22 & 18 \\
$\mathrm{rGO}$ & 1.03 & 60 & &
\end{tabular}

$\left(32 \mathrm{~mJ} \mathrm{~cm}^{-2}\right)$ at $32 \mathrm{~mJ} \mathrm{~cm}{ }^{-2}$ laser fluence with that of GO film (only selected $2 \theta$ range shown in the figure). The XRD patterns show a diffraction peak at $2 \theta=9.7^{\circ}$ which refers to an interlayer spacing of $9.1 \AA$. Another peak also appears at $2 \theta=69.3^{\circ}$ related to Si substrate and was used to normalize the pattern. The XRD patterns of the GO and rGO films normalized by the Si peak. As observed, the sharp diffraction signal of GO was significantly reduced in intensity by laser irradiation which indicates removal of the oxygenated functional groups. On the other hand, there is no trace of graphite in GO and rGO films corresponding to the $2 \theta$ peak of $26.4^{\circ}$. Therefore, XRD observations are in agreement with the Raman and XPS results, confirming the transfer of GO to rGO. Similar results were obtained in other studies ${ }^{\mathbf{3 1 , 5 0}}$ where they used glass and quartz as the substrate.

Further evidence of confirming of GO films reduction by laser irradiation was obtained using monitoring their electrical properties. The electrical behavior of the rGO films was studied by measuring the electrical resistance of the films irradiated at various laser fluences. Electrical resistance measurements of rGO films were conducted using a 4-point probe method. However, the electrical resistance of pristine GO films was measured by common method since they had a primarily high resistance of the order of G $\Omega$. Fig. 6(a) shows the dependence of electrical resistance of the thin films on laser fluences. As observed, laser irradiation at low laser fluences caused a sharp drop of the electrical resistance of GO films. It was labeled as a reduction region in the figure. Since the electrical resistances of GO films strongly depend on the oxygen content, this can be explained by a comparison of $248 \mathrm{~nm}$ photons energy $(5 \mathrm{eV})$ of the $\mathrm{KrF}$ laser with those of $\mathrm{C}$ and $\mathrm{O}$ bonds in GO. Since $\mathrm{C}=\mathrm{C}$ and $\mathrm{C}=\mathrm{O}$ bonds (6.36 and $7.69 \mathrm{eV}$, respectively) are much stronger than $\mathrm{C}-\mathrm{C}$ and $\mathrm{C}-\mathrm{O}$ bonds $(3.61$ and $3.73 \mathrm{eV}$, respectively), the energy of the photons of the $\mathrm{KrF}$ laser causes breaking $\mathrm{C}-\mathrm{C}$ and $\mathrm{C}-\mathrm{O}$ bonds and so electrical resistance significantly drops. A reduction of resistance by four orders of magnitudes was obtained at laser fluence from 14 to $32 \mathrm{~mJ}$ $\mathrm{cm}^{-2}$. However, the higher values of laser fluence cause a slight increase in resistance (ablation region). Therefore, laser irradiation at lower laser fluences results in reducing GO films, whereas at slightly higher values GO film is ablated to some

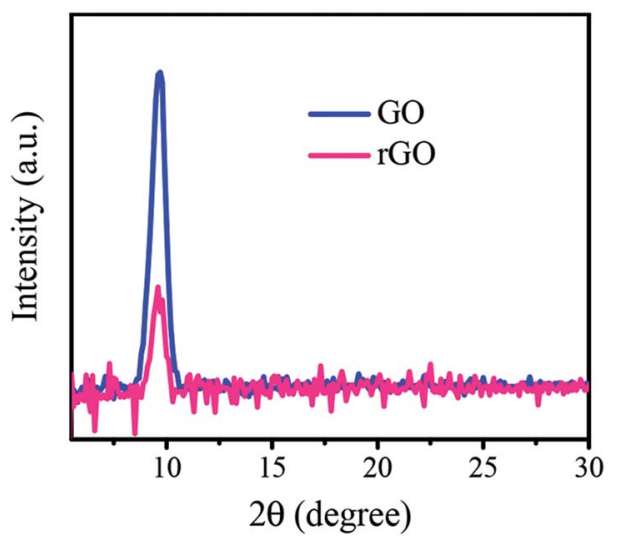

Fig. 5 XRD patterns of GO and rGO films irradiated at $32 \mathrm{~mJ} \mathrm{~cm} \mathrm{~cm}^{-2}$ laser fluence normalized by Si peak. 

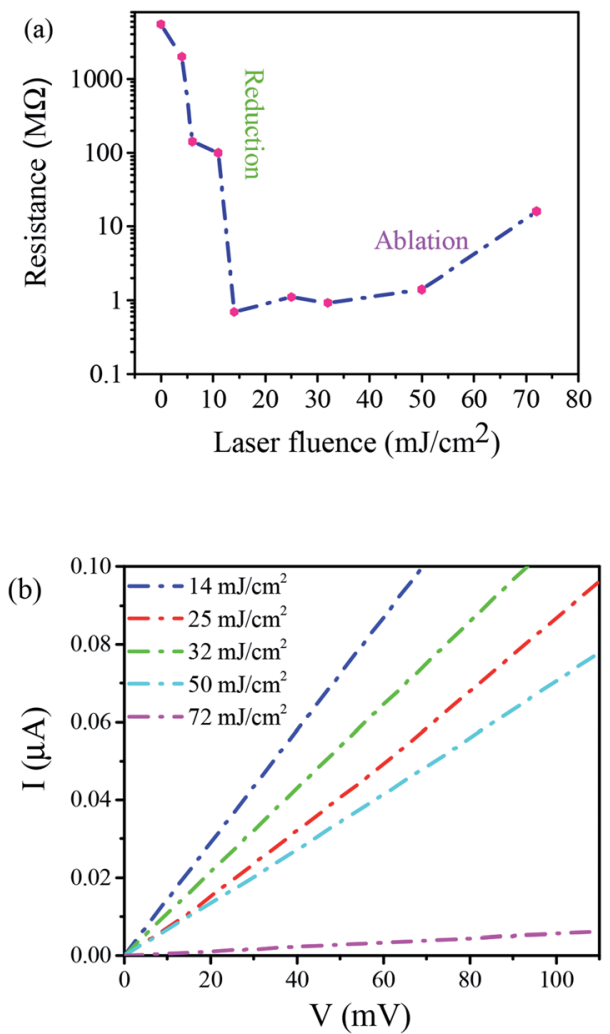

Fig. 6 (a) Electrical resistance of rGO films as a function of laser fluence and (b) $I-V$ curves of microcircuits produced at different laser fluences.

extent which, in turn, causes the increase of electrical resistance, as were explained by Yung et al. ${ }^{48}$

The results of measured $I-V$ characteristics to determine electrical resistances of rGO films at different laser fluences were presented in Fig. 6(b). Linear dependence between current and voltage shows stable conductivity of microcircuits produced under different laser fluences. These results show the capability to control the electric properties of GO films through an insulator to conductor transition by changing laser fluence.

\section{Conclusions}

In summary, laser irradiation of GO films was studied under various laser fluences in the air environment. Raman spectra of irradiated GO films showed the sharper and narrower 2D band with increasing laser fluence confirming transformation to the graphene-like structures upon laser processing. Moreover, laser irradiation of GO films resulted in the considerable elimination of the oxygenated functional groups as confirmed by XPS of irradiated GO films. Finally, KrF laser irradiation process of GO films resulted in fabrication of conductive rGO microcircuits with the reduced electrical resistances that can be used in microelectronics devices.

\section{Conflicts of interest}

There are no conflicts to declare.

\section{References}

1 A. Beltaos, A. Kovačević, A. Matković, U. Ralević, D. j. Jovanović and B. Jelenković, Phys. Scr., 2014, 162, 014015-014019.

2 A. Roberts, D. Cormode, C. Reynolds, T. Newhouse-Illige, B. J. LeRoy and A. S. Sandhu, Appl. Phys. Lett., 2011, 99, 051912.

3 Q. Mei, K. Zhang, G. Guan, B. Liu, S. Wang and Z. Zhang, Chem. Commun., 2010, 46, 7319-7321.

4 M. Lorenzoni, F. Brandi, S. Dante, A. Giugni and B. Torre, Sci. Rep., 2013, 3, 1954-1962.

5 M. F. El-Kady, V. Strong, S. Dubin and R. B. Kaner, Science, 2012, 335, 1326-1330.

6 Y. Jia, X. Gong, P. Peng, Z. Wang, Z. Tian, L. Ren, Y. Fu and H. Zhang, Nano-Micro Lett., 2016, 8(4), 336-346.

7 P. Russo, A. Hu and G. Compagnini, Nano-Micro Lett., 2013, 5(4), 260-273.

8 M. F. El-Kady and R. B. Kaner, ACS Nano, 2014, 8(9), 87258729.

9 J. Shang, L. Ma, J. Li, W. Ai, T. Yu and G. G. Gurzadyan, Sci. Rep., 2012, 2(792), 1-8.

10 C. Petridis, Y. H. Lin, K. Savva, G. Eda, E. Kymakis, T. D. Anthopoulos and E. Stratakis, Appl. Phys. Lett., 2013, 102, 093115.

11 Y. Wu, H. Tao, S. Su, H. Yue, H. Li, Z. Zhang, Z. Ni and X. Chen, Sci. Rep., 2017, 7, 46583-46591.

12 L. Kou, H. He and C. Gao, Nano-Micro Lett., 2010, 2(3), 177183.

13 T. Chang and Z. Chen, Appl. Surf. Sci., 2015, 359, 543-549.

14 X. Shi, X. Li, L. Jiang, L. Qu, Y. Zhao, P. Ran, Q. Wang, Q. Cao, T. Ma and Y. Lu, Sci. Rep., 2015, 5, 17557-17566.

15 X. D. Chen, Z. B. Liu, W. S. Jiang, X. Q. Yan, F. Xing, P. Wang, Y. Chen and J. G. Tian, Sci. Rep., 2013, 3, 3216-3221.

16 M. Sygletou, C. Petridis, E. Kymakis and E. Stratakis, Adv. Mat, 2017, 29, 1700335.

17 D. Konios, C. Petridis, G. Kakavelakis, M. Sygletou, K. Savva, E. Stratakis and E. Kymakis, Adv. Funct. Mater., 2015, 25, 2213.

18 E. Kymakis, K. Savva, M. M. Stylianakis, C. Fotakis and E. Stratakis, Adv. Funct. Mater., 2013, 23, 2742.

19 M. M. Stylianakis, M. Sygletou, K. Savva, G. Kakavelakis, E. Kymakis and E. Stratakis, Adv. Opt. Mater., 2015, 3(5), 658-666.

20 D. Konios, G. Kakavelakis, C. Petridis, K. Savva, E. Stratakis and E. Kymakis, J. Mater. Chem. A, 2016, 4(5), 1612-1623.

21 K. Savva, Y. H. Lin, C. Petridis, E. Kymakis, T. D. Anthopoulos and E. Stratakis, J. Mater. Chem. C, 2014, 2(29), 5931-5937.

22 E. Stratakis, K. Savva, D. Konios, C. Petridis and E. Kymakis, Nanoscale, 2014, 6(12), 6925-6931.

23 C. Petridis, D. Konios, M. M. Stylianakis, G. Kakavelakis, M. Sygletou, K. Savva, P. Tzourmpakis, M. Krassas, 
N. Vaenas, E. Stratakis and E. Kymakisa, Nanoscale Horiz., 2016, 1(5), 375-382.

24 N. Balis, E. Stratakis and E. Kymakis, Mater. Today, 2016, 19(10), 580-594.

25 V. Singh, D. Joung, L. Zhai, S. Das, S. I. Khondaker and S. Seal, Prog. Mater. Sci., 2011, 56, 1178-1271.

26 A. Bagri, C. Mattevi, M. Acik, Y. J. Chabal, M. Chhowalla and V. B. Shenoy, Nat. Chem., 2010, 2, 581-588.

27 M. Lorenzoni, A. Giugni, E. D. Fabrizio, F. Pérez-Murano, A. Mescola and B. Torre, J. Nanotechnol., 2015, 26, 285301285310.

28 T. N. Blanton and D. Majumdar, Powder Diffr., 2013, 28(2), 68-71.

29 I. Karteri, S.. ü. Karatas and F. Y. glu, Appl. Surf. Sci., 2014, 318, 74-78.

30 H. F. Teoh, Y. Tao, E. S. Tok, G. W. Ho and C. H. Sow, J. Appl. Phys., 2012, 112, 064309.

31 Y. Zhang, L. Guo, S. Wei, Y. He, H. Xia, Q. Chen, H. B. Sun and F. S. Xiao, Nano Today, 2010, 5, 15-20.

32 W. Zhang, L. Li, Z. B. Wang, A. A. Pena, D. J. Whitehead, M. L. Zhong, Z. Lin and H. W. Zhu, Appl. Phys. A, 2012, 109, 291-297.

33 X. Ye, J. Long, Z. Lin, H. Zhang, H. Zhu and M. Zhong, Carbon, 2014, 68, 784-790.

34 V. Kiisk, T. Kahro, J. Kozlova, L. Matisen and H. Alles, Appl. Surf. Sci., 2013, 276, 133-137.

35 T. Huang, J. Long, M. Zhong, J. Jiang, X. Ye, Z. Lin and L. Li, Appl. Surf. Sci., 2013, 273, 502-506.

36 B. Wetzel, C. Xie, P.-A. Lacourt, J. M. Dudley and F. Courvoisier, Appl. Phys. Lett., 2013, 103, 241111.

37 S. Mortazavi, M. Mollabashi and S. I. Shah, Appl. Surf. Sci., 2018, 428, 94-97.
38 C. Cheng, R. He, C. Romero, J. R. V. de Aldana and F. Chen, Appl. Phys. Lett., 2017, 111, 241901.

39 D. A. Sokolov, C. M. Rouleau, D. B. Geohegan and T. M. Orlando, Carbon, 2013, 53, 81-89.

40 R. Trusovas, K. Ratautas, G. Raciukaitis, J. Barkauskas, L. Stankeviciene, G. Niaura and R. Mažeikiene, Carbon, 2013, 52, 574-582.

41 W. Cai, B. Zeng, J. Liu, J. Guo, N. Li, L. Chen and H. Chen, Appl. Surf. Sci., 2013, 284, 113-117.

42 L. Guo, H. B. Jiang, R. Q. Shao, Y. L. Zhang, S. Y. Xie, J. N. Wang, X. B. Li, F. Jiang, Q. D. Chen, T. Zhang and H. B. Sun, Carbon, 2012, 50, 1667-1673.

43 Y.-L. Zhang, L. Guo, H. Xia, Qi-D. Chen, J. Feng and H.-B. Sun, Adv. Opt. Mater., 2014, 2, 10-28.

44 Yu-Q. Liu, Y.-L. Zhang, Y. Liu, H.-B. Jiang, D.-D. Han, B. Han, J. Feng and H.-B. Sun, Chem. Rec., 2016, 16(3), 1244-1255.

45 E. Kymakis, C. Petridis, T. D. Anthopoulos and E. Stratakis, IEEE J. Sel. Top. Quantum Electron., 2014, 20(1), 106-115.

46 C. Petridis, Y. H. Lin, K. Savva, G. Eda, E. Kymakis, T. D. Anthopoulos and E. Stratakis, Appl. Phys. Lett., 2013, 102(9), 093115.

47 H. Y. Chen, D. Han, Y. Tian, R. Shao and S. Wei, Chem. Phys., 2014, 430, 13-17.

48 K. C. Yung, H. Liem, H. S. Choy, Z. C. Chen, K. H. Cheng and Z. X. Cai, J. Appl. Phys., 2013, 113, 244903.

49 B. Y. Zhou, Q. Bao, B. Varghese, L. A. L. Tang, C. K. Tan, C. H. Sow and K. P. Loh, Adv. Mater., 2010, 22, 67-71.

50 V. L. Borgne, H. Bazi, T. Hayashi, Y. A. Kim, M. Endo and M. A. El Khakani, Carbon, 2014, 77, 857-867.

51 R. Arul, R. N. Oosterbeek, J. Robertson, G. Xu, J. Jin and M. C. Simpson, Carbon, 2016, 99, 423-431. 